\title{
Role of phosphorylated ERK in amygdala neuronal apoptosis in single-prolonged stress rats
}

\author{
HAO LIU ${ }^{1}$, HAIBO LI ${ }^{1}$, AIJUN XU ${ }^{2}$, QUAN KAN ${ }^{2}$ and BIN LIU ${ }^{1}$ \\ ${ }^{1}$ Department of Neurology, Affiliated Hospital, North China Coal Medical University; ${ }^{2}$ Department of Histology \\ and Embryology, North China Coal Medical University, Tangshan 063000, P.R. China
}

Received August 3,2010; Accepted September 6, 2010

DOI: $10.3892 / \mathrm{mmr} .2010 .362$

\begin{abstract}
Studies have shown that single-prolonged stress (SPS) can induce the apoptotic process in the amygdala. In the present study, we aimed to detect expression of phosphorylated p44/42 extracellular signal-regulated kinase (pERK1/2) and apoptosis-related Bax and Bcl-2 and apoptotic cell death in the amygdala region in SPS rats as well as the relation between pERK1/2 and apoptosis. A total of 75 male Wistar rats were randomly divided into control, SPS and PD98059-SPS groups. Rats in the SPS and PD98059-SPS groups were treated with the SPS procedure and were injected with solvent or PD98059 (an inhibitor of ERK), respectively, into the amygdala $30 \mathrm{~min}$ before exposure to SPS. The expression of pERK1/2 was detected using immunohistochemistry and Western blotting. The expression of Bax and Bcl-2 was detected using Western blotting and RT-PCR; TUNEL-staining was employed for the detection of apoptotic cells in the amygdala. The results showed that the expression of $\mathrm{pERK} 1 / 2$, the ratio of $\mathrm{Bax} / \mathrm{Bcl}-2$ and the TUNEL-positive cell rate significantly increased in the SPS group. After the rats were infused with PD98059, these indices were abolished. In the SPS rat brain, we found that the apoptotic process in the amygdala region was induced by pERK $1 / 2$, and this may be related to the abnormal function of the amygdala in post-traumatic stress disorder.
\end{abstract}

\section{Introduction}

Post-traumatic stress disorder (PTSD), a stress-related mental disorder, develops after endurance of a life-threatening traumatic experience and consists of re-experiencing, avoidance, numbing and hyperarousal. Various brain regions, particularly the medial prefrontal cortex (mPFC), hippocampus and amygdala, are involved in the pathophysiology of PTSD.

Correspondence to: Dr Hao Liu, Department of Neurology, Affiliated Hospital, North China Coal Medical University, No. 73 Jianshe South Road, Tangshan 063000, P.R. China

E-mail: liuhao938@163.com

Key words: extracellular signal regulated kinase, amygdala, posttraumatic stress disorder, apoptosis
The amygdala, one of the key regions in the limbic system of the brain, has been documented to play an important role in emotional memory, such as fear or rage (1). It has been well-documented that the amygdala undergoes abnormal functioning in PTSD (2-4), and a serial of behavioral changes in PTSD may be due to the amygdala (5). Studies have shown that the volume of the amygdala decreases during PTSD (6-8), and our recent study demonstrated that the apoptotic process in the amygdala region may be related to the pathogenesis of the abnormal function of the amygdala in PTSD (9).

The extracellular signal regulated kinase (ERK) is highly sensitive to stress and is closely associated with cognitive and mood processing (10-12). It is well-established that stress exposure activates the ERK1/2 signaling pathway $(11,12)$, and it has been speculated that the ERK signaling pathway in the lateral amygdala is involved in anxiety $(13,14)$. Generally, activation of ERK1/2 promotes cell survival; however, under certain conditions, ERK1/2 exhibits pro-apoptotic functions (15). Bax, one of the pro-apoptotic proteins, and Bcl-2, one of the anti-apoptotic proteins, play a crucial role in the control of apoptotis $(16,17)$. In addition, the $\mathrm{Bax} / \mathrm{Bcl}-2$ ratio appears to be a critical threshold parameter for apoptotic events (18).

Single-prolonged stress (SPS), one of the animal models proposed for PTSD (19), was shown to induce enhanced inhibition of the hypothalamic-pituitary-adrenal (HPA) axis, which is a putative neuroendocrinological hallmark of PTSD. Rats that experience SPS also exhibit behavioral abnormalities (enhanced anxiety) that mimic the symptoms of PTSD $(20,21)$. Expression of $\mathrm{Bax} / \mathrm{Bcl}-2$, the number of apoptotic cells and the number of TUNEL-positive cells were found to be induced by SPS (9). However, whether the ERK1/2 pathway is activated during SPS in the amygdala and its role in PTSD induced by SPS are not as yet clear. In the present study, we aimed to determine changes in the pERK1/2 level and the effects of ERK1/2 on the expression of Bax/Bcl-2 and apoptosis in the amygdala of SPS rats.

\section{Materials and methods}

Experimental animals. A total of 75 male Wistar rats (weighing 180-220 g) purchased from the Experimental Animal Center of North China Coal Medical University were used in this study, and all rats were reared in the experimental animal facility for a week to acclimatize the aminals to the 
new environment (temperature, $18-20^{\circ} \mathrm{C}$; humidity, $50-60 \%$; lights on, 07:00-19:00) before the exprement. Standard food pellets and tap water were available ad libitum. All procedures followed the National Guidelines on Animal Care.

Drug infusion procedures. Before intra-amygdala administration, the rats were cannulated under pentobarbital anesthesia (40 $\mathrm{mg} / \mathrm{kg}$, i.p.), bilaterally in the amygdala region according to the atlas (22). PD98059 (Sigma, USA), an inhibitor of ERK, was dissolved in dimethyl sulfoxide (DMSO) $(100 \mathrm{mM})$ and stored at $-20^{\circ} \mathrm{C}$. The solution was diluted to $1 \mathrm{mM}$ with $0.01 \mathrm{M}$ PBS before use. Bilateral intra-amygdala infusions of the solution were designed using 30 -gauge injection needles connected to a $5-\mu 1$ Hamilton microsyringe by polyethylene tubing. The tip of the injection needle was placed $4.0-\mathrm{mm}$ ventral to the skull surface. A volume of $0.5 \mu \mathrm{l}$ was administered for $2 \mathrm{~min}$ to each side of the amygdala followed by an additional 2-min waiting period before the injection needles were extracted. After infusion, the animals were returned to their cage. The control rats received equal amount of solvents.

Group assignment and SPS procedure. The rats were randomly divided into three groups: the control, SPS and PD98059-SPS groups. The rats in the SPS and PD98059-SPS groups were treated with the SPS procedure, and solvent or PD98059, respectively, was injected into the bilateral amygdala $30 \mathrm{~min}$ before exposure to SPS. The control rats were administered an equal volume of solvent into the amygdala. The model of PTSD was carried out by SPS according to a previous report (23). The rats were restrained for $2 \mathrm{~h}$ and then forced to swim for $20 \mathrm{~min}\left(24^{\circ} \mathrm{C}\right)$, followed by ether anesthesia. They were then allowed to remain in their home cages without interference until they were euthanized $1 \mathrm{~h}$ or 7 days after exposure to SPS. The control rats lived in their individual home cages with no handling and were euthanized after $1 \mathrm{~h}$ or 7 days. Each group consisted of 25 rats; 5 rats were used for immunohistochemical analysis, 10 for Western blotting (ERK1/2 or $\mathrm{Bax} / \mathrm{Bcl}-2), 5$ for reverse transcriptase polymerase chain reaction (RT-PCR) and 5 rats were used for TUNEL.

Brain tissue preparation and immunohistochemical analysis of $p E R K 1 / 2$. One hour after exposure to SPS, 5 rats of each group were transcardially infused with $200-300 \mathrm{ml}$ of pre-cooled saline through the ascending aorta, followed by $300 \mathrm{ml}$ of $0.01 \mathrm{M}$ PBS (pH 7.4) containing 4\% pre-cooled paraformaldehyde. The whole brains were rapidly removed after perfusion fixation with $4 \%$ paraformaldehyde in $0.01 \mathrm{M}$ PBS. Samples were dehydrated in alcohol, paraffin-embedded and sectioned $(5 \mu \mathrm{m})$. The sections were incubated with $10 \%$ normal goat serum for $30 \mathrm{~min}$ at $37^{\circ} \mathrm{C}$ and antibody I (mouse monoclonal anti-pERK1/2 antibody; Cell Signaling, Beverly, MA, USA; 1:200 dilution) overnight at $4^{\circ} \mathrm{C}$ and antibody II (goat polyclonal anti-mouse IgG; Boster Biological Technology Ltd., China; 1:200 dilution) for $1 \mathrm{~h}$ at $37^{\circ} \mathrm{C}$. The sections were then incubated with the avidin-biotin peroxidase complex (Boster Biological Technology Ltd; 1:200 dilution) for $1 \mathrm{~h}$ at $37^{\circ} \mathrm{C}$, and immunocomplexes were finally visualized with $0.05 \%$ DAB. Each slide was randomly selected from five visual fields in the amygdala (x40). We recorded the optical density (OD) of the positive cells in each field to evaluate the average OD. The OD values of the immunoreactivity of pERK1/2-immunopositive cells were analyzed using a MetaMorph/DPIO/BX41 morphology image analysis system.

Western blotting of pERK1/2, Bax and Bcl-2. One hour and 7 days after exposure to SPS, 5 rats of each group were sacrificed to determine pERK1/2 and Bax/Bcl-2, respectively, by Western blotting. The brains were removed, and the amygdala was dissected according to the atlas (22). Tissue samples were homogenized in an ice-cold lysis buffer containing $5 \mathrm{mM}$ EDTA, $1 \%$ SDS, $1 \%$ NP-40, $0.5 \%$ sodium deoxycholate, $10 \mathrm{mM}$ CHAPS, $1 \%$ Triton X-100, $0.25 \mathrm{mM}$ PMSF, $5 \mu \mathrm{g} / \mathrm{ml}$ leupeptin and $50 \mathrm{mM}$ Tris- $\mathrm{HCl}(\mathrm{pH}$ 8.2). Crude homogenates were incubated on ice for $30 \mathrm{~min}$ and centrifuged at $15,000 \mathrm{xg}$ for $30 \mathrm{~min}$ at $4^{\circ} \mathrm{C}$. The supernatant was collected for protein assay and stored at $-70^{\circ} \mathrm{C}$. Samples ( $30 \mu \mathrm{g}$ of protein per lane) were separated on 10\% SDS-PAGE and transferred onto PVDF membranes. The membranes were blocked in blocking solution $(5 \%$ skimmed milk, $10 \mathrm{mM}$ Tris- $\mathrm{HCl}, 100 \mathrm{mM}$ $\mathrm{NaCl}, 0.01 \%$ Tween-20) for $2 \mathrm{~h}$ at room temperature and immersed in the mouse monoclonal anti-pERK1/2 antibody (1:1000) overnight at $4^{\circ} \mathrm{C}$. Membranes were washed thrice for $10 \mathrm{~min}$ each in TBST $(10 \mathrm{mM}$ Tris- $\mathrm{HCl}, 100 \mathrm{mM} \mathrm{NaCl}$, $0.01 \%$ Tween-20) and incubated for $2 \mathrm{~h}$ with the horseradish peroxidase-conjugated secondary antibody, goat polyclonal anti-mouse $\operatorname{IgG}(1: 2500)$. After the membranes were washed, the specific bands were detected by the ECL system (Amersham Pharmacia Biotech, Buckinghamshire, UK). Western blotting for total ERK1/2, Bax, Bcl-2 and $\beta$-actin were performed in the same way. The bands were analyzed by the Gel Image Analysis system (Tanon 2500R, Shanghai, China). Each pERK or Bax (Bcl-2) band was normalized with total ERK1/2 or $\beta$-actin, respectively, and the values were expressed as a ratio of the intensity.

Total RNA extraction and RT-PCR for Bax and Bcl-2 mRNA. Total RNA was extracted from the amygdala using TRIzol (Invitrogen, USA). One microgram of total RNA was reversetranscribed into cDNA. cDNA was amplified using a RNA PCR kit (AM Ver. 3.0, Takara Bio, Otsu, Japan). The primers of Bax, Bcl-2 and $\beta$-actin were designed by Primer Premier 5.0 software and synthesized by Sangon Biotech Limited Co. (Shanghai, China). The primer sequences were: Bax, 5'-TTC ATC CAG GAT CGA GCA GA-3' (upstream primer) and 5'-GCA AAG TAA AGG CAA CG-3' (downstream primer); Bcl, 5'-CTG GTG GAC AAC ATC GCT CTG-3' (upstream primer) and 5'-GGT CTG CTG ACC TCA CTT GTG-3' (downstream primer); $\beta$-actin, 5'-ATC ACC CAC ACT GTG CCC ATC-3' (upstream primer) and 5'-ACA GAG TAC TTG CGC TCA GGA-3' (downstream primer). Their product size was 263,228 and $542 \mathrm{bp}$, respectively. The amplification profile included i) denaturation at $94^{\circ} \mathrm{C}$ for $5 \mathrm{~min}$, ii) 36 additional cycles at $95^{\circ} \mathrm{C}$ for $30 \mathrm{sec}, 60^{\circ} \mathrm{C}$ for $50 \mathrm{sec}, 72^{\circ} \mathrm{C}$ for $45 \mathrm{sec}$ (for Bax gene), 32 additional cycles at $95^{\circ} \mathrm{C}$ for 30 sec, $62^{\circ} \mathrm{C}$ for $50 \mathrm{sec}, 72^{\circ} \mathrm{C}$ for $40 \mathrm{sec}$ (for Bcl-2 gene), and iii) extension at $72^{\circ} \mathrm{C}$ for $8 \mathrm{~min}$. The PCR products were separated on $1.5 \%$ agarose gel by electrophoresis, and the density of each band was analyzed using the Gel Image analysis system. The levels of Bax and Bcl-2 mRNA were normalized to $\beta$-actin. 


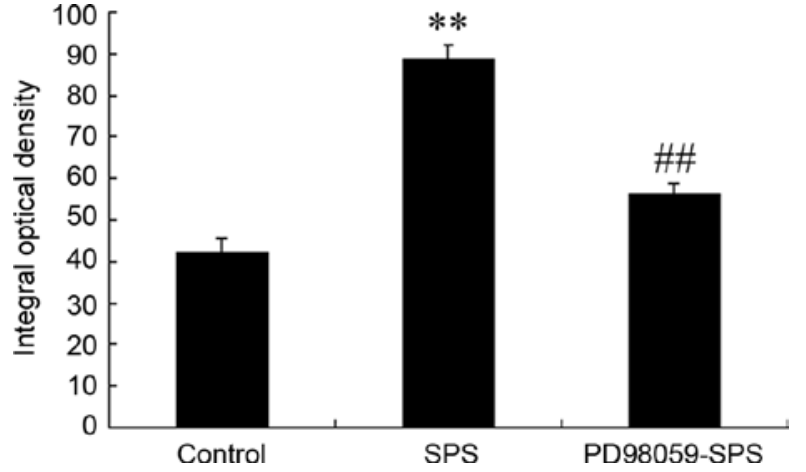

Figure 1. Quantification of the optical density of pERK-positive cells in the amygdala by immunohistochemical staining. $\mathrm{n}=5$ for each group. Statistical analysis was carried out by one-way ANOVA $\left(F_{(2,12)}=52.064 ; \mathrm{P}<0.01\right)$ followed by Tukey's test. ${ }^{* *} \mathrm{P}<0.01$ compared to the control group, ${ }^{\# \#} \mathrm{P}<0.01$ compared to the SPS group.

A

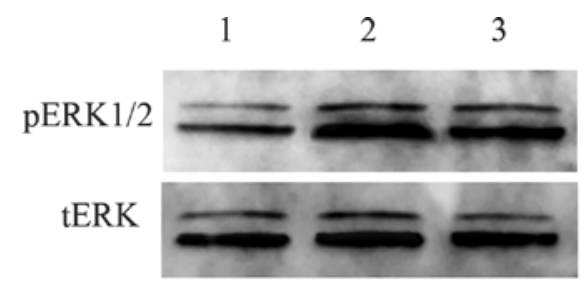

B

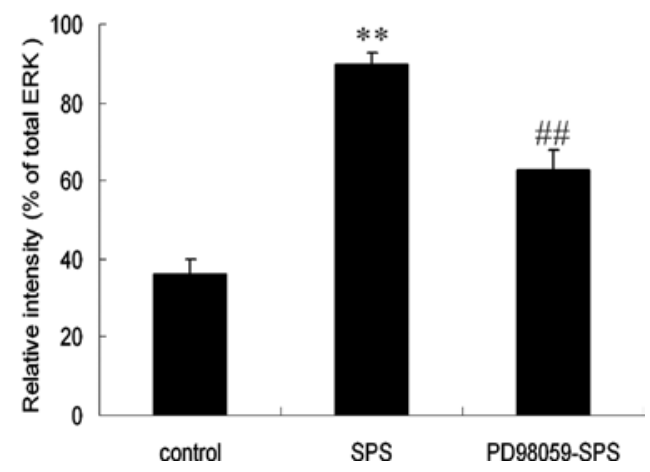

Figure 2. Change in pERK1/2 protein in the amygdala using Western blotting. (A) Typical photomicrographs of the results are shown. Lane 1, control group; 2, SPS group; 3, SPS-PD98059 group. (B) Relative levels of pERK1/2 are shown. $\mathrm{n}=5$ for each group. Statistical analysis was carried out by one-way ANOVA $\left(F_{(2,12}=44.019 ; \mathrm{P}<0.01\right)$ followed by Tukey's test, ${ }^{* *} \mathrm{P}<0.01$ compared to the control group, ${ }^{\# \#} \mathrm{P}<0.01$ compared to the SPS group.

TUNEL staining. Sections were washed three times $(5 \mathrm{~min}$ each) in $0.01 \mathrm{M}$ PBS, and permeabilized in proteinase $\mathrm{K}$ for $10 \mathrm{~min}$. Endogenous peroxidase was deactivated by $0.3 \%$ hydrogen peroxide. After washing three times once more, the sections were incubated with TDT at $37^{\circ} \mathrm{C}$ for $1 \mathrm{~h}$ and incubated with the antibody at $37^{\circ} \mathrm{C}$ for $1 \mathrm{~h}$. Sections were stained by DAB after hematoxylin post-staining, mounted and observed under a light microscope. Five slides were randomly selected from each group, and each slide was randomly selected from five visual fields (x40) in the amygdala. The number of TUNEL-positive cells was counted. The TUNELpositive cell rate $=$ (number of TUNEL-positive cells/total cells) x $100 \%$.
A

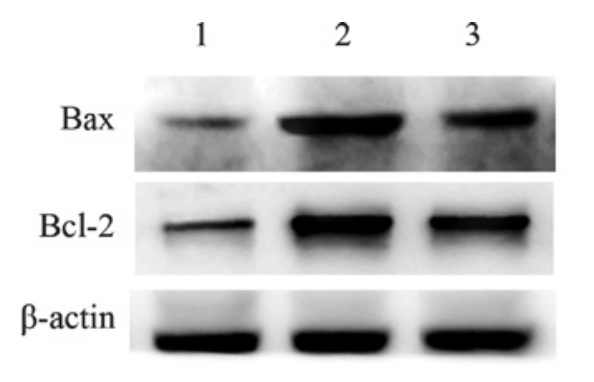

B

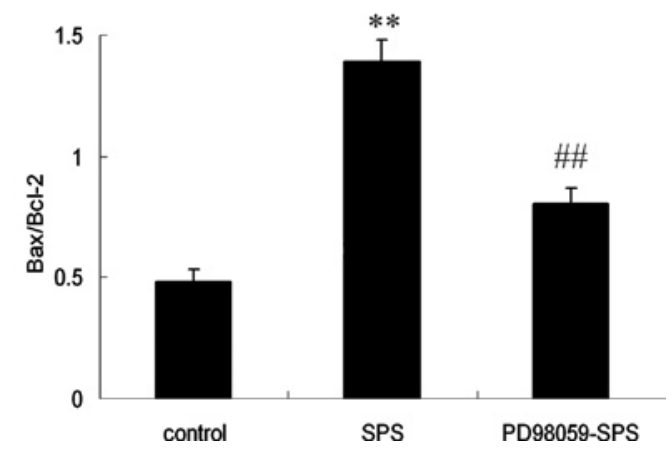

Figure 3. Change in Bax and Bcl-2 in the amygdala of the various rat groups. (A) Typical results of Western blotting are shown. Lane 1, control group rats; 2, SPS group rats; 3, SPS-PD98059 group rats. (B) Change in the Bax/Bcl-2 ratio is shown. $\mathrm{n}=5$ for each group. Statistical analysis was carried out by one-way ANOVA $\left(F_{(2,12)}=46.924 ; \mathrm{P}<0.01\right)$ followed by Tukey's test, ${ }^{* *} \mathrm{P}<0.01$ compared to the control group, ${ }^{\# \#} \mathrm{P}<0.01$ compared to the SPS group.

Statistical analysis. All values were presented as the means \pm standard error of means (SEM) and were analyzed using SPSS11.5. Statistical significance was determined by one-way analysis of variance (ANOVA), followed by Tukey's test when appropriate. A P-value $<0.05$ was considered to indicate a statistically significant difference.

\section{Results}

Immunohistochemical staining of $p E R K 1 / 2$. The immunohistochemical staining results are shown in Fig. 1. The OD of the pERK1/2-positive cells in the control group was low, while that in the SPS rats was significantly increased $(\mathrm{P}<0.01)$. After the rats were infused with PD98059, the OD in the amygdala was significantly decreased $(\mathrm{P}<0.01)$.

Western blot analysis for $p E R K 1 / 2$. The result of the Western blot analysis of pERK1/2 is shown in Fig. 2. The pERK1/2 proteins were detected in two bands at $42 / 44 \mathrm{kDa}$ (Fig. 2A). The density of the pERK1/2 bands significantly increased in the SPS rats $(\mathrm{P}<0.01), 2-3$ times when compared with that of the control rats $(\mathrm{P}<0.01)$ (Fig. 2B). After the rats were infused with PD98059, the SPS-induced ERK1/2 hyperphosphorylation in the amygdala was significantly decreased $(\mathrm{P}<0.01)$ (Fig. 2B).

Western blot analysis of the Bax/Bcl-2 ratio. The result of the Western blot analysis of the Bax/Bcl-2 ratio is shown in Fig. 3 . The result showed that the ratio of $\mathrm{Bax} / \mathrm{Bcl}-2$ significantly increased in the SPS rats $(\mathrm{P}<0.01)$. After the rats were infused 
A

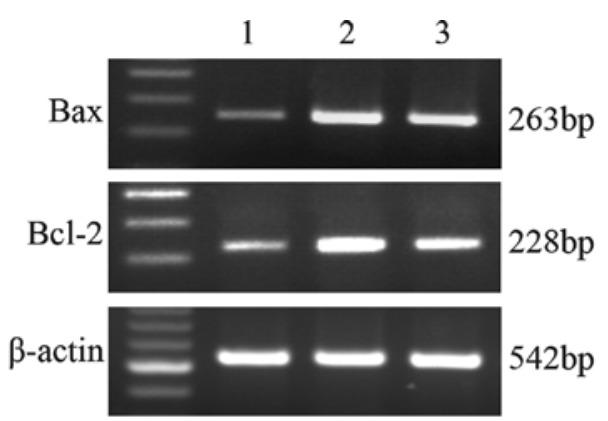

B

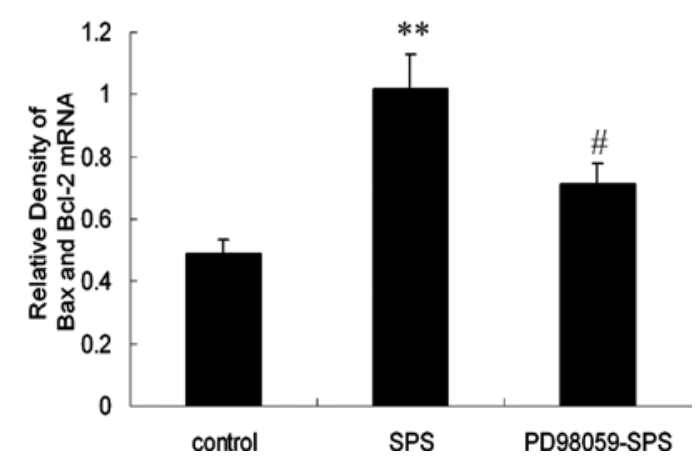

Figure 4. Change in Bax and Bcl-2 mRNA in the amygdala of rats. (A) Typical results of RT-PCR are shown. Lane 1, control group; 2, SPS group; 3, SPSPD98059 group. (B) Relative density of Bax and Bcl-2 mRNA is shown. $\mathrm{n}=5$ for each group. Statistical analysis was carried out by one-way ANOVA $\left(F_{(2,12)}=22.740, \mathrm{P}<0.01\right)$ followed by Tukey's test, ${ }^{* *} \mathrm{P}<0.01$ compared to the control group, ${ }^{*} \mathrm{P}<0.05$ compared to the SPS group.

with PD98059, the SPS-induced increased ratio of Bax/Bcl-2 in the amygdala was significantly decreased $(\mathrm{P}<0.01)$.

RT-PCR analysis of Bax and Bcl-2 $m R N A$. The result of the RT-PCR analysis of Bax and Bcl-2 mRNA is shown in Fig. 4. The result of RT-PCR showed a significant increase in the SPS group compared with the control group $(\mathrm{P}<0.01)$. The ratio of $\mathrm{Bax} / \mathrm{Bcl}-2$ was found to significantly increase in the SPS rats $(\mathrm{P}<0.01)$. After the rats were infused with PD98059, the SPS-induced increased ratio of Bax/Bcl-2 in the amygdala was significantly reduced $(\mathrm{P}<0.01)($ Fig. 4).

TUNEL staining. The TUNEL-positive cell rate of each group is shown in Fig. 5. Positive cells were rarely detected in the amygdala of the control group. In contrast, the number of TUNEL-positive cells was higher in the amygdala of the SPS rats $(\mathrm{P}<0.01)$, and $\mathrm{PD} 98059$ reduced the positive cell rate $(\mathrm{P}<0.01)$.

\section{Discussion}

PTSD exhibits four major types of characteristic symptoms: re-experiencing, avoidance, numbing and hyperarousal, suggesting a heightened fear response. PTSD is thought to involve a dysregulation of mPFC and amygdala activity in response to fear. Some brain regions, particularly the amygdala and the hippocampus, are involved in the pathophysiology of PTSD. The amygdala is the main output center for the response to fearful stimuli (24) and has been documented to be responsible for enhancement of explicit memory associated

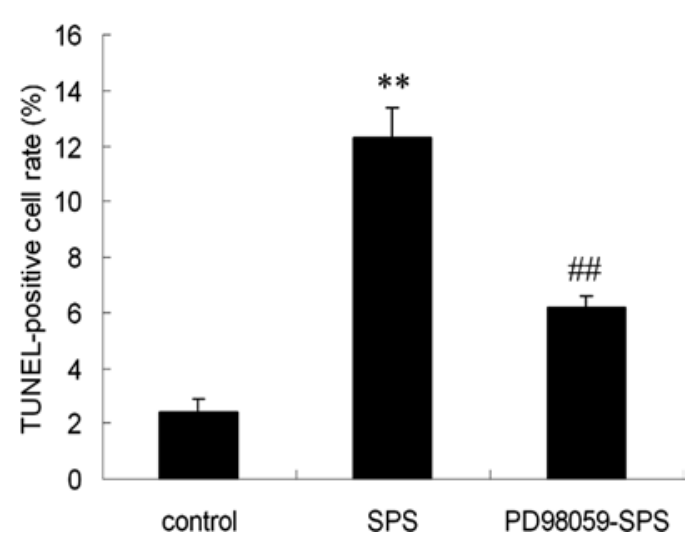

Figure 5. TUNEL-positive cell rate in the amygdala. $n=5$ for each group. Statistical analysis was carried out by one-way ANOVA $\left(F_{(2,12)}=47.861\right.$; $\mathrm{P}<0.01)$ followed by Tukey's test, ${ }^{* *} \mathrm{P}<0.01$ compared to the control group, ${ }^{\#} \mathrm{P}<0.01$ compared to the SPS group.

with emotional arousal $(25,26)$. The hippocampus is another major component of the limbic system. The amygdala is closely related to the hippocampus, and the clinical course of PTSD is driven by pathophysiological changes in these brain regions. The basolateral nucleus is the largest subregion in the amygdala (27). It is the key region of fear initiation. In this study, we selected the amygdala as the region of interest in which to study PTSD and focus on observing changes in the basolateral nucleus.

Abundant evidence suggests that the volume of the amygdala in PTSD is significantly smaller $(6,8)$. However, the cause for this decrease in the amygdala volume during PTSD is unclear. Ding and co-researchers detected the expression of apoptosis-related genes and observed morphological changes in the amygdala neurons of PTSD rats (9). Apoptosis is regulated by different classes of proteins including pro-apoptotic protein Bax and anti-apoptotic protein Bcl-2. The Bax/Bcl-2 ratio appears to be a critical threshold parameter for apoptotic events $(18,28)$, and TUNEL-staining demonstrates cellular apoptosis.

In the present study, we investigated the relationship between apoptosis and ERK hyperphosphorylation induced by SPS. The results showed that ERK1/2 phosphorylation in the amygdala was significantly increased in the SPS rats, suggesting the involvement of the ERK signal transduction pathway in the response to stress. In other words, ERK phosphorylation can be induced by SPS. Another significant finding of this study is that the Bax/Bcl-2 ratio and TUNELpositive cell rate in the amygdala increased after the rats were exposed to SPS, suggesting that amygdala neuronal apoptosis is induced by SPS. Apoptosis might play an important role in the decrease in the volume of the amygdala by PTSD. Moreover, this study showed that the increase in apoptosis induced by SPS was significantly reduced by PD98059, an inhibitor of ERK. ERK phosphorylation may be one of the factors that induces amygdala neruonal apoptosis.

In conclusion, we demonstrated the occurrence of apoptosis in the amygdala and found that it was associated with ERK1/2 phosphorylation. The results suggest that the ERK signal transduction pathway and apoptosis may play an impor- 
tant role in PTSD. Detailed mechanisms of the ERK signal system and apoptosis in the pathophysiology of stress-related disorders warrant further investigation.

\section{References}

1. McGaugh JL and Cahill L: Interaction of neuromodulatory systems in modulating memory storage. Behav Brain Res 83 31-38, 1997.

2. Rauch SL, Whalen PJ, Shin LM, McInerney SC, Macklin ML, Lasko NB, Orr SP and Pitman RK: Exaggerated amygdala response to masked facial stimuli in posttraumatic stress disorder: a functional MRI study. Biol Psychiatry 47: 769-776, 2000.

3. Shin LM, Orr SP, Carson MA, Rauch SL, Macklin ML, Lasko NB, Peters PM, Metzger LJ, Dougherty DD, Cannistraro PA, Alpert NM, Fischman AJ and Pitman RK: Regional cerebral blood flow in the amygdala and medial prefrontal cortex during traumatic imagery in male and female Vietnam veterans with PTSD. Arch Gen Psychiatry 61: 168-176, 2004.

4. Liberzon I, Taylor SF, Amdur R, Jung TD, Chamberlain KR, Minoshima S, Koeppe RA and Fig LM: Brain activation in PTSD in response to trauma-related stimuli. Biol Psychiatry 45: 817-826, 1999.

5. Cui H, Sakamoto H, Higashi S and Kawata M: Effects of singleprolonged stress on neurons and their afferent inputs in the amygdala. Neuroscience 152: 703-712, 2008.

6. Lindauer RJ, Vlieger EJ, Jalink M, Olff M, Carlier IV, Majoie CB, den Heeten GJ and Gersons BP: Smaller hippocampal volume in Dutch police officers with posttraumatic stress disorder. Biol Psychiatry 56: 356-363, 2004.

7. Matsuoka Y, Yamawaki S, Inagaki M, Akechi T and Uchitomi Y: A volumetric study of amygdala in cancer survivors with intrusive recollections. Biol Psychiatry 54: 736-743, 2003.

8. Karl A, Schaefer M, Malta LS, Döfel D, Rohleder N and Werner A: A meta-analysis of structural brain abnormalities in PTSD. Neurosci Biobehav Rev 30: 1004-1031, 2006.

9. Ding L, Han F, and Shi Y: Single-prolonged stress induces apoptosis in the amygdala in a rat model of post-traumatic stress disorder. J Psychiatr Res 44: 48-55, 2010.

10. Hetman M and Gozdz A: Role of extracellular signal regulated kinases 1 and 2 in neuronal survival. Eur J Biochem 271: 2050-2055, 2004.

11. Gerrits M, Westenbroek C, Koch T, Grootkarzijn A and ter Horst GJ: Increased limbic phosphorylated extracellular-regulated kinase 1 and 2 expression after chronic stress is reduced by cyclic 17 beta-estradiol administration. Neuroscience 142: 1293-1302, 006

12. Zheng G, Chen Y, Zhang X, Cai T, Liu M, Zhao F, Luo W and Chen J: Acute cold exposure and rewarming enhanced spatial memory and activated the MAPK cascades in the rat brain. Brain Res 1239: 171-180, 2008.
13. Paul S, Olausson P, Venkitaramani DV, Ruchkina I, Moran TD, Tronson N, Mills E, Hakim S, Salter MW, Taylor JR and Lombroso PJ: The striatal-enriched protein tyrosine phosphatase gates long-term potentiation and fear memory in the lateral amygdala. Biol Psychiatry 61: 1049-1061, 2007.

14. Tronson NC, Schrick C, Fischer A, Sananbenesi F, Pagès G, Pouysségur $\mathrm{J}$ and Radulovic J: Regulatory mechanisms of fear extinction and depression-like behavior. Neuropsychopharmacology 33: 1570-1583, 2008.

15. $\mathrm{Lu} \mathrm{Z}$ and $\mathrm{Xu} \mathrm{S}$ : ERK1/2 MAP kinases in cell survival and apoptosis. IUBMB Life 58: 621-631, 2006.

16. Panaretakis T, Pokrovskaja K, Shoshan MC and Grandér D: Activation of Bak, Bax, and $\mathrm{BH} 3$-only proteins in the apoptotic response to doxorubicin. J Biol Chem 277: 44317-44326, 2002.

17. Konopleva M, Konoplev S, Hu W, Zaritskey AY, Afanasiev BV and Andreeff M: Stromal cells prevent apoptosis of AML cells by up-regulation of anti-apoptotic proteins. Leukemia 16: 1713-1724, 2002

18. Jarskog LF, Selinger ES, Lieberman JA and Gilmore GH: Apoptotic proteins in the temporal cortex in schizophrenia: high bax/bcl-2 ratio without caspase-3 activation. Am J Psychiatry 161: 1109-1115, 2004.

19. Kohda K, Harada K, Kato K, Hoshino A, Motohashi J, Yamaji T, Morinobu S, Matsuoka N and Kato N: Glucocorticoid receptor activation is involved in producing abnormal phenotypes of singleprolonged stress rats: a putative post-traumatic stress disorder model. Neuroscience 148: 22-33, 2007.

20. Imanaka A, Morinobu S, Toki S and Yamawaki S: Importance of early environment in the development of post-traumatic stress disorder-like behaviors. Behav Brain Res 173: 129-137, 2006.

21. Takahashi T, Morinobu S, Iwamoto Y and Yamawaki S: Effect of paroxetine on enhanced contextual fear induced by single prolonged stress in rats. Psychopharmacology 189: 165-173, 2006.

22. Paxinos G and Watson C: The Rat Brain in Stereotaxic Coordinates. Academic Press, San Diego, 1998.

23. Liberzon I, Krstov M and Young EA: Stress-restress: effects on ACTH and fast feedback. Psychoneuroendocrinology 22: 443-453, 1997

24. Charney DS: Psychobiological mechanisms of resilience and vulnerability: implications for successful adaptation to extreme stress. Am J Psychiatry 161: 195-216, 2004.

25. McGaugh JL: The amygdala modulates the consolidation of memories of emotionally arousing experiences. Annu Rev Neurosci 27: 1-28, 2004.

26. Hamann S: Cognitive and neural mechanisms of emotional memory. Trends Cogn Sci 5: 394-400, 2001.

27. Sims KS and Williams RS: The human amygdaloid complex: a cytologic and histochemical atlas using Nissl, myelin, acetylcholinesterase and nicotinamide adenine dinucleotide phosphate diaphorase staining. Neuroscience 36: 449-472, 1990.

28. Cregan SP, Dawson VL and Slack RS: Role of AIF in caspasedependent and caspase-independent cell death. Oncogene 23 2785-2796, 2004. 